\title{
Occupational pesticide exposure and respiratory health: a large-scale cross-sectional study in three commercial farming systems in Ethiopia
}

\author{
Beyene Negatu, ${ }^{1,2}$ Hans Kromhout, ${ }^{1}$ Yalemtshay Mekonnen, ${ }^{3}$ Roel Vermeulen ${ }^{1}$
}

\begin{abstract}
- Additional material is
published online only. To view please visit the journal online (http://dx.doi.org/10.1136/ thoraxinl-2016-208924).

'Division of Environmental Epidemiology, Institute for Risk Assessment Sciences, Utrecht University, Utrecht, The Netherlands

2Pesticide Risk Reduction

Project-Ethiopia, Federal Ministry of Agriculture, Addis

Ababa, Ethiopia

${ }^{3}$ Collage of Natural \&

Computational Sciences, Addis Ababa University, Addis Ababa, Ethiopia
\end{abstract}

\section{Correspondence to} Beyene Negatu, Institute for Risk Assessment Sciences, Utrecht University, Utrecht 3584 CM, The Netherlands; b.negatu@uu.nl, beyene. negatu@gmail.com

Received 23 May 2016 Revised 19 October 2016 Accepted 25 October 2016 Published Online First 22 November 2016

\begin{abstract}
Rationale In the last decade, due to expansion of greenhouses and irrigated farms, the use of pesticides in Ethiopia has increased 6-13-fold leading to potential health risks.

Objective To investigate if occupational exposure to pesticides is associated with respiratory health effects in farmers and farm workers from commercial farming systems.

Methods We performed two cross-sectional surveys comprising different farming systems. In the first survey we studied respiratory symptoms among 1104 subjects of which 601 were occupationally exposed to pesticides (ie, 256 pesticide applicators, 345 re-entry workers) and 503 unexposed individuals. The second survey, carried out 2 years later in the same farming regions, additionally included lung function measurement and comprised a total of 387 study subjects of which 206 were occupationally exposed to pesticides (142 applicators and 64 re-entry workers) and 180 unexposed individuals.
\end{abstract}

Results We observed increased risks for chronic cough and shortness of breath $(\mathrm{OR}=3.15,95 \% \mathrm{Cl} 1.56$ to 6.36 and $\mathrm{OR}=6.67,95 \% \mathrm{Cl} 2.60$ to 17.58 ) among the exposed subjects as compared with unexposed individuals in the first survey. These results were corroborated in the second survey where we also observed reductions in $\mathrm{FEV}_{1}(140 \mathrm{~mL})$, forced expiratory flow $25 \%-75 \%(550 \mathrm{~mL} / \mathrm{s})$ and risk of $\mathrm{FEV}_{1} / \mathrm{FVC}$ ratio $<0.8(\mathrm{OR}=4.31,95 \% \mathrm{Cl} 2.11$ to 8.81$)$ among pesticide exposed workers.

Conclusions These findings indicate an increased risk of adverse respiratory health among workers exposed to pesticides. As those effects occurred in young workers (mean age 27 years) and within a relative short duration of exposure (4 years) implementation of stringent occupational health measures are warranted.

\section{INTRODUCTION}

Exposure to pesticides is one of the main occupational health hazards faced by farm workers. ${ }^{1}$ Occupational exposure to pesticides can occur while preparing and applying pesticides and during tasks in recently sprayed fields. ${ }^{2}$ Occupational exposure to pesticides has been linked with diverse health effects including respiratory health effects. ${ }^{3-8}$

Studies, including low income, middle income countries (LMICs), have shown that occupational exposure to pesticides is associated with respiratory health symptoms and a reduction in lung function

\section{Key messages}

What is the key question?

- Do current occupational pesticide use patterns in Ethiopian agriculture affect respiratory health of farmers and farm workers including female farm workers and those from cut-flower greenhouses?

\section{What is the bottom line?}

- We observed exposure-response associations between occupational pesticides exposure and chronic respiratory symptoms and lung function impairment in two consecutive cross-sectional surveys.

\section{Why read on?}

- The respiratory effects were observed in young workers (mean age 27 years) who only recently and for a relatively short time (average 4 years) have been occupationally exposed to pesticides.

parameters. $^{9-15}$ Though Ethiopia has endorsed a labour proclamation in order to minimise and control risks in occupational settings, ${ }^{16}$ previous studies have shown higher prevalences of respiratory symptoms ${ }^{17} 18$ and reductions in respiratory function ${ }^{19} 20$ in individuals occupationally exposed to pesticides.

Although, these studies indicate a possible association between pesticide exposure and respiratory health they were mostly performed among (male) applicators in classical farming systems such as large-scale open farms (LSOFs) with the exception of Hanssen et $a l^{18}$ who studied the newly established cut-flower industry in Ethiopia. Recently, due to expansions of new farming systems such as large-scale greenhouses (LSGHs) and small-scale irrigated farms (SSIFs) there has been a stark increase in pesticide use intensity (6-13-fold). ${ }^{21}$ Though there is a difference in type and intensity of pesticide use among different farming systems in Ethiopia, organophosphates (eg, chlorpyrifos) are the most intensively used class of pesticides. Also organochlorine (eg, dichlorodiphenyltrichloroethane (DDT)) and phosponoglycine (eg, glyphosate) were reported to be used intensively in Ethiopia. ${ }^{19} 21$ Additionally poor pesticide-related knowledge, attitude and practices were reported 
among Ethiopian farmers and farm workers. ${ }^{21}$ As the workforce is relatively young and rapidly increasing in these new farming systems it is pertinent to monitor the health status of this workforce. To date, there is no study in Ethiopia that examined respiratory health, including objective lung function measurements, of both applicator and re-entry farm workers in these new and growing farming systems.

In this study we aimed to examine whether occupational pesticide exposure is associated with respiratory symptoms and lung function impairments in applicators and re-entry workers selected from three commercial farming systems in Ethiopia.

\section{METHODS}

Study area and population

The study was conducted in the central part of Ethiopia where abundant hydrological resources from the rift valley lakes and Awash river are available for the three farming systems (LSGH, LSOF and SSIF) (figure 1). Those commercial farms use significant amounts of pesticides to produce horticultural crops; roses and cuttings in LSGH, vegetable, fruit and cotton in LSOF, and vegetables in SSIF.

The study consisted of two consecutive cross-sectional surveys conducted in the same study area and farms. The first survey (2012) focused on respiratory symptoms while the second survey (2014) extended on this first survey by focusing both on respiratory symptoms and lung function parameters. Participation in both surveys was on a voluntary basis. In the first survey verbal consent was obtained and participation was on an anonymous basis. In the second survey written consent was obtained.

In the first survey a total of 1104 subjects were selected. Of the 1104 subjects selected, 601 were occupationally exposed to pesticides (at least for a year) and the rest 503 were unexposed farmers selected from rain-fed/subsistence agricultural areas (where pesticides due to economic reasons are not used; $n=408)$ and office workers from LSOF $(n=95)$. Of the 601 exposed, 256 were applicators and 345 were re-entry workers. The unexposed individuals resided in the same geographical area as the exposed subjects (figure 1). Applicators were defined as workers who are directly involved in pesticide application activities (ie, pesticide mixers/loaders, pesticide sprayers and application supervisors) whereas re-entry workers were defined as workers who enter fields after they have been treated with pesticides or handle the produce (eg, harvesters).

In the first survey we aimed to include all applicators and a randomly selected subset of the re-entry workers from each of the farming systems. The method of random sampling for re-entry workers differed slightly by the farming systems due to differences in work practices. Generally, in SSIFs there is at least a farmer or farm worker (usually applicator) and on harvesting days several re-entry workers are present. In the case of LSGH and LSOF, usually there is a small crew of applicators while there are many re-entry workers. Due to the large number of re-entry workers in LSGH and LSOF, we randomly selected re-entry workers.

Recruitment of farm workers in SSIF was done by randomly selecting five primary farmers' cooperatives from Meki-Batu vegetables and fruit growers' union. Each member's farm of the selected primary cooperatives was visited and, applicators and re-entry workers present were invited to participate. In case of LSOF, four units were randomly selected from nine units of two big farms; Merti-jeju (four units) and Nuraera (five units) which are under the umbrella of the Upper Awash Agro Industry Enterprise. Applicators and re-entry workers were invited to participate. In the case of LSGH, two farms were randomly selected from two clusters in the study area. All applicators and randomly selected re-entry workers (with a sampling proportion of about 10\%) were invited to participate. Unexposed individuals were selected randomly from six rain-fed agriculture subdistricts, three from each of the two districts in the study area. Unexposed office workers in case of LSOF were selected based on the employment list obtained from the farm.

The second survey was carried out 2 years after the first survey in the same study area and selected farms and farming systems, but with a focus on applicators in all three farming systems and re-entry workers in LSGH. A total of 387 subjects
Figure 1 Location map of the study area.

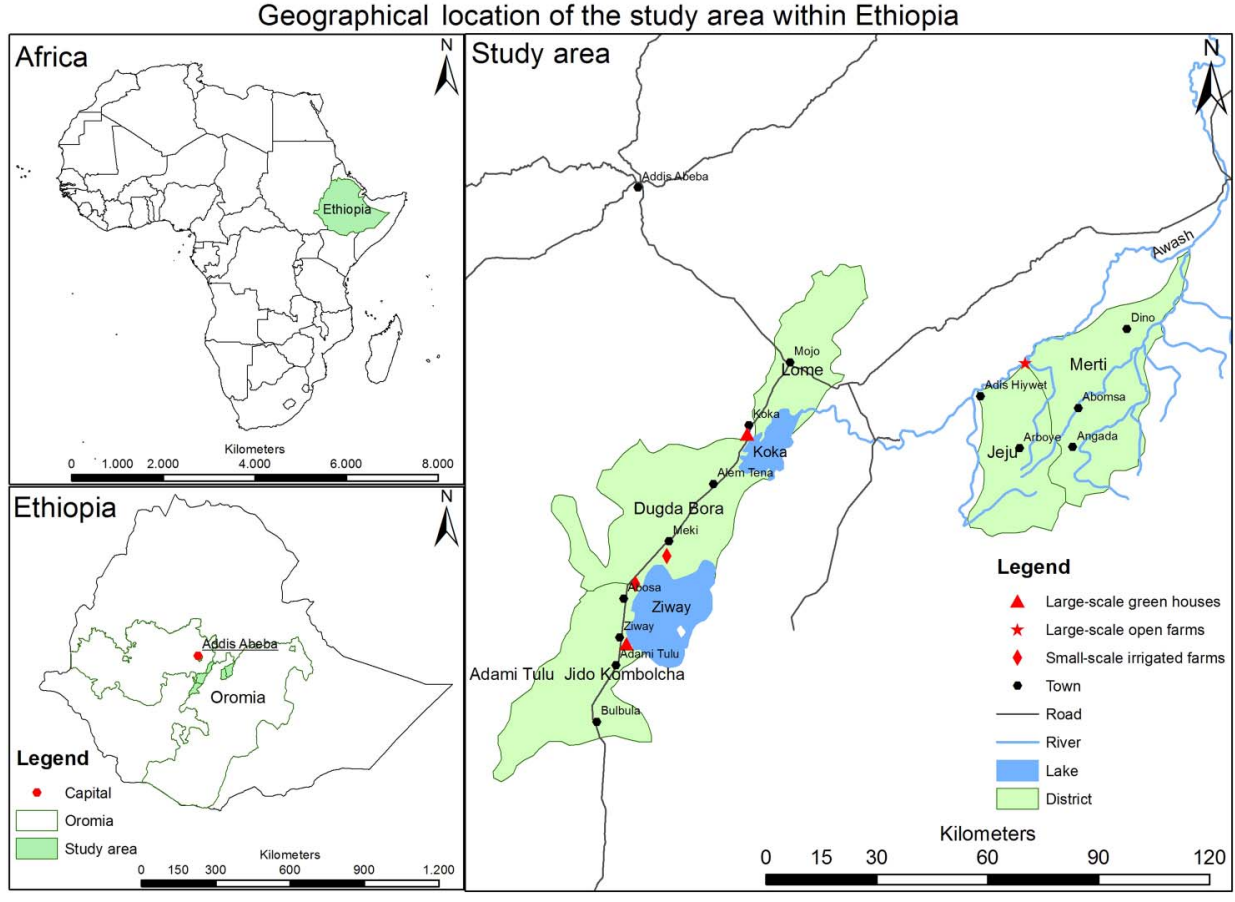


of which 206 were exposed (142 applicators and 64 re-entry workers) and 180 unexposed individuals was included.

Similar selection procedures as that of the first survey were followed both in exposed and unexposed populations. But only two primary cooperatives were included of the previously selected five in SSIFs and two subdistricts were included out of the six in the first survey of the unexposed. Similar to the first survey unexposed individuals resided in the same geographical area as the exposed. In both, surveys participants were identified and approached in consultation with or through farmers' cooperatives and farm managers in case of exposed workers and with health and agricultural extension workers in case of unexposed rain-fed farmers. In all of the random selections of farms or participants random numbers were generated and assigned to an alphabetical list.

\section{Data collection}

In the first survey a structured questionnaire (see online supplementary material 1) was used to obtain data on pesticide exposure, respiratory symptoms, and sociodemographic and lifestyle factors. Respiratory symptoms were assessed using a standardised questionnaire based on the British Medical Research Council which was used previously in Ethiopia. ${ }^{20}$ The questionnaire was translated to Amharic (the national language of Ethiopia) and back translated to English for consistency and piloted on 32 farm workers and finally administered by two trained data collectors.

In the second survey the same questionnaire was used with the addition of atopic symptoms and height and weight measurements. We also performed lung function tests using the Easy One model 2001spirometer. Spirometry parameters of FVC, $\mathrm{FEV}_{1}, \mathrm{FEV}_{1}$ to $\mathrm{FVC}$ ratio and forced expiratory flow from $25 \%$ to $75 \%$ of vital capacity (FEF 25\%-75\%) were considered. Tests were done in sitting positions and repeated until three good manoeuvres were obtained. The questionnaire and lung function surveys were done by two trained data collectors.

Manual reviewing of the spirometry data was done by a certified lung function technician. From the quality assured tests the attempt with the largest sum of FVC and $\mathrm{FEV}_{1}$ was kept in the final analysis, as recommended by the European Respiratory Society and American Thoracic Society Task Force. ${ }^{22}$ This procedure resulted in 320 (89\%) out of the 360 surveyed being retained in the analyses $(160(85 \%)$ and 160 (93\%)) among the exposed and unexposed subjects, respectively.

\section{Pesticide exposure assessment}

Pesticide exposure was assessed both qualitatively and semiquantitatively as previously described in Negatu et al. ${ }^{23}$ The exposures assessment was based on exposure estimates obtained from exposure algorithms developed separately for applicators and re-entry workers. In short, the algorithm for estimation of cumulative exposure of applicators was adapted from the agricultural health study ${ }^{24}$ and included exposure modifying factors that reflect (I) intensity of exposure (eg, pesticide use intensity), (II) exposure protection (eg, personal protection devices) and (III) exposure period (eg, application years). The algorithm for estimation of cumulative exposure in re-entry workers consists of (I) re-entry exposure intensity score (based on job title and farming system), (II) exposure protection, and (III) exposure period. We also estimated the intensity of daily exposure for both applicators and re-entry workers.

\section{Data analysis}

Field data were entered using Epi Data V.3 and analysed using Stata/SE V.12.00. Student's t-test and Fisher's exact test were used to analyse differences between exposed and unexposed subjects. Potential confounding factors, which are known or suspected to have effects on respiratory health were a priori selected; sociodemographic factors (eg, income), life style factors (eg, smoking) and previous disease conditions (eg, pulmonary TB). Potential confounding factors that changed the associations between pesticide exposure and lung health (respiratory symptoms and lung function) $\geq 10 \%$ were included in the final multivariate (logistic) regression model (ie, gender (where relevant), age, body mass index (BMI) (second survey), smoking status, past pneumonia, and income, marital status and khat chewing status). Data from 19 (2\%) individuals from the first survey and four (1\%) individuals from the second survey with a history of pulmonary TB were excluded from the analyses (figure 2). In all analyses occupationally unexposed individuals were used as a reference group stratified by gender (ie, male unexposed, for applicators and male re-entry workers in their respective models, and female unexposed for female re-entry workers). In the analyses using semiquantitative exposure estimates, exposed individuals were classified into two groups based on the median of cumulative and daily exposure estimates. We used a cut-off value for the $\mathrm{FEV}_{1} / \mathrm{FVC}$ ratio of $<0.8$ in the analysis as the more clinically accepted ratio of $\mathrm{FEV}_{1} / \mathrm{FVC}<0.7$ in this young population (average 27 years old)
Figure 2 Flow of the number of participants in the first and second surveys of the study on respiratory health of farmers and farm workers from three commercial farming systems in Ethiopia. PTB, pulmonary tuberculosis.

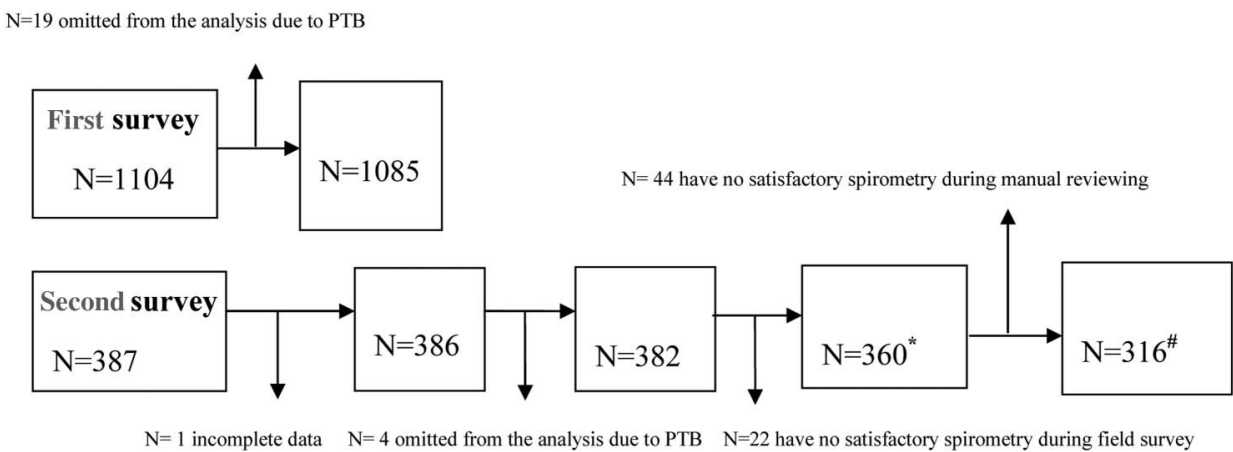

* Only data from subjects with a satisfactory manoeuvre (quality grades A to C) were included, based on automatic quality control messages of Easy One model 2001 spirometer. ${ }^{\#}$ The manual reviewing was done by a certified lung function technician as recommended by the latest European Respiratory Society (ERS) and American Thoracic Society (ATS) Task Force. 
is low resulting in low statistical power. However, exploratory analyses using a $\mathrm{FEV}_{1} / \mathrm{FVC}<0.7$ resulted in similar effects albeit that risks were estimated to be imprecise. Model assumption checks were performed for logistic regression models (ie, deviance, Pearson $\chi^{2}$ and Hosmer-Lemeshow tests). In all analyses $\mathrm{p}<0.05$ was considered statistically significant.

\section{RESULTS}

\section{Sociodemographic and life style factors}

Characteristics of the study population of each of the two surveys are shown in table 1 . Participants were relatively young with an average age of $27 \cdot 7 \pm 6 \cdot 33$ (SD) years and $26.7 \pm 6.47$ (SD) years and had a low prevalence of smoking $(4.6 \%$ and $5.5 \%)$ in the first and second surveys, respectively. Exposed subjects worked on average 4.4 years and 3.4 years with pesticides in the first and second surveys, respectively. Income and khat chewing were higher in unexposed subjects whereas history of alcohol consumption was higher in exposed subjects in the second survey.

Applicators from the second survey had higher estimated values of cumulative and daily pesticide exposure than applicators from the first survey. Similarly, re-entry workers from the second survey had higher estimates of daily and cumulative exposure than re-entry workers from the first survey. This difference remained when only the scores of LSGH of the first survey were considered for re-entry workers as re-entry workers in the second survey were only from LSGH.

\section{Respiratory symptoms}

Generally, a higher prevalence of respiratory symptoms among both the exposed and unexposed subjects was reported in the second survey as compared with the first survey (table 2). Respiratory symptoms were more prevalent in the exposed than unexposed subjects in both surveys but reached statistical

Table 1 Sociodemographic characteristics by survey and exposure status

\begin{tabular}{|c|c|c|c|c|c|c|c|c|c|c|}
\hline \multirow[b]{3}{*}{ Study variables } & \multicolumn{5}{|c|}{ First survey (2012) } & \multicolumn{5}{|c|}{ Second survey (2014) } \\
\hline & \multicolumn{2}{|c|}{ Exposed $(n=588)$} & \multicolumn{2}{|c|}{ Unexposed $(n=497)$} & \multirow[b]{2}{*}{ p Value } & \multicolumn{2}{|c|}{ Exposed $(n=205)$} & \multicolumn{2}{|c|}{ Unexposed $(n=177)$} & \multirow[b]{2}{*}{ p Value } \\
\hline & Number & Per cent & Number & Per cent & & Number & Per cent & Number & Per cent & \\
\hline \multicolumn{11}{|l|}{ Gender } \\
\hline Male & 318 & 54.08 & 250 & 50.30 & 0.21 & 142 & 69.27 & 112 & 63.28 & 0.22 \\
\hline Female & 270 & 45.92 & 247 & 49.70 & & 63 & 30.73 & 65 & 36.72 & \\
\hline \multicolumn{11}{|l|}{ Educational level } \\
\hline No formal education & 35 & 5.95 & 48 & 9.66 & $<0.05^{* * *}$ & 16 & 7.81 & 19 & 10.73 & $<0.05^{*}$ \\
\hline Grade 1-6 & 274 & 46.60 & 297 & 59.76 & & 83 & 40.49 & 46 & 25.99 & \\
\hline Grade 7-8 & 155 & 26.36 & 95 & 19.11 & & 46 & 22.44 & 55 & 31.07 & \\
\hline Grade 9-12 & 118 & 20.07 & 49 & 9.86 & & 58 & 28.29 & 51 & 28.81 & \\
\hline Diploma & 6 & 1.02 & 6 & 1.21 & & 2 & 0.98 & 5 & 2.82 & \\
\hline Degree & - & & 2 & 0.40 & & - & & 1 & 0.56 & \\
\hline \multicolumn{11}{|l|}{ Marital status } \\
\hline Married & 330 & 56.12 & 360 & 72.43 & $<0.05^{* * *}$ & 104 & 50.73 & 110 & 62.15 & $<0.05^{* *}$ \\
\hline Divorced & 28 & 4.76 & 12 & 2.41 & & 7 & 3.41 & - & & \\
\hline Widowed & 12 & 2.04 & 6 & 1.21 & & 5 & 2.44 & 1 & 0.56 & \\
\hline Single & 218 & 37.07 & 119 & 23.94 & & 89 & 43.41 & 66 & 37.29 & \\
\hline Alcohol drinking & 360 & 61.22 & 289 & 58.15 & 0.30 & 159 & 63.86 & 90 & 36.14 & $<0.05^{* * *}$ \\
\hline Smoking & 32 & 5.44 & 18 & 3.62 & 0.15 & 10 & 4.88 & 11 & 6.21 & 0.32 \\
\hline \multirow[t]{2}{*}{ Khat chewing $\dagger$} & 63 & 10.71 & 65 & 13.08 & 0.23 & 31 & 15.12 & 49 & 27.68 & $<0.05^{* *}$ \\
\hline & Mean & SD & Mean & SD & & Mean & SD & Mean & SD & \\
\hline Age (years) & 27.39 & 6.58 & 27.97 & 6.01 & 0.13 & 26.59 & 6.47 & 26.92 & 7.04 & 0.63 \\
\hline \multicolumn{11}{|l|}{ Male } \\
\hline Height (metre) & - & & - & & - & 1.70 & 0.07 & 1.71 & 0.06 & 0.25 \\
\hline BMI & - & & - & & - & 21.45 & 2.80 & 20.90 & 2.57 & 0.15 \\
\hline \multicolumn{11}{|l|}{ Female } \\
\hline Height (metre) & - & & - & & - & 1.56 & 0.06 & 1.58 & 0.06 & 0.12 \\
\hline BMI & - & & - & & - & 21.94 & 2.39 & 21.25 & 2.38 & 0.13 \\
\hline Monthly income (birr) & 1025.48 & 574.33 & 968.68 & 548.88 & 0.10 & 1167.67 & 592.12 & 1330.01 & 742.61 & $<0.05^{*}$ \\
\hline Duration of pesticide exposure (years) & 4.43 & 3.49 & - & & - & 3.41 & 2.49 & - & & - \\
\hline Cumulative exposure (EU) & & & - & & - & & & - & & - \\
\hline Applicators $(n=250)$ & 7680.00 & 12708.53 & & & & 11722.21 & 15369.84 & & & \\
\hline Re-entry workers $(n=338)$ & 22593.70 & 28809.58 & & & & 28384.47 & 24973.10 & & & \\
\hline Daily exposure (EU) & & & - & & - & & & - & & - \\
\hline Applicators $(n=142)$ & 18.99 & 13.41 & & & & 21.96 & 12.46 & & & \\
\hline Re-entry workers $(n=63)$ & 21.14 & 19.42 & & & & 29.18 & 18.20 & & & \\
\hline
\end{tabular}

tKhat is an evergreen shrub of eastern Africa and Arabia; its leaves have narcotic properties.

${ }^{*} \mathrm{p}<0.05,{ }^{* *} \mathrm{p}<0.01,{ }^{* * *} \mathrm{p}<0.001$

BMI, body mass index; EU, exposure units. 
significance only for chronic cough and shortness of breath (table 2). Multiple logistic regression indicated significant differences between exposed and unexposed subjects in respiratory symptoms of chronic cough $(\mathrm{OR}=3.15,95 \%$ CI 1.56 to 6.36 and $\mathrm{OR}=5.76,95 \% \mathrm{CI} 1.90$ to 17.42 ) and shortness of breath $(\mathrm{OR}=6.67,95 \%$ CI 2.60 to 17.58 and $\mathrm{OR}=4.09,95 \%$ CI 2.12 to 7.90 ) in both the first and second surveys, respectively (table 3).

In exposure-response analyses based on the median of the exposure distribution revealed exposure-response associations for chronic cough and shortness of breath among male applicators, and female and male re-entry workers in both surveys (except male re-entry worker in the first survey for shortness of breath and female re-entry workers in the second survey for chronic cough) with ORs of the highest exposure group, for male applicators in the first survey (chronic cough $(\mathrm{OR}=8.14)$ ); female re-entry (chronic cough $(\mathrm{OR}=3.02)$ and shortness of breath $(\mathrm{OR}=7.86)$ ); and male re-entry worker (chronic cough $(\mathrm{OR}=21.24))$. In the second survey results were essentially similar with male applicators (chronic cough $(\mathrm{OR}=13.15)$ and shortness of breath $(\mathrm{OR}=6.63))$; and female re-entry workers (shortness of breath $(\mathrm{OR}=6.51)$ ). In addition, an effect was observed for wheeze among male applicators in the second survey (wheeze $(\mathrm{OR}=4.65)$ ). Analyses using daily exposure resulted in similar observations albeit somewhat less strong (see online supplementary material 2).

\section{Lung function measurements}

As shown in table 2 a significant difference between pesticides exposed and unexposed in mean values of respiratory parameters with the exception of FVC were observed. Also the prevalence of $\mathrm{FEV}_{1}$ to $\mathrm{FVC}$ ratio $<0.8$ was higher in the pesticide exposed than unexposed subjects. After controlling for potential confounders, pesticide exposure was associated with reduced respiratory parameters except FVC (ie, FEV $F_{1}$ (l) $\beta=$ $-0.14(95 \% \mathrm{CI}-0.25$ to -0.03$)$ and FEF $25 \%-75 \%(\mathrm{~L} / \mathrm{s}) \beta=$ $-0.55(95 \% \mathrm{CI}-0.80$ to -0.31$))$ and a significant increased OR for the $\mathrm{FEV}_{1} / \mathrm{FVC}$ ratio $(<0.8)$ of $4.31(95 \%$ CI 2.11 to 8.81 ) (table 4).

Analyses with cumulative exposure among the exposed above and below the median showed an exposure-response association for the $\mathrm{FEV}_{1}$ to $\mathrm{FVC}$ ratio $(<0.8)$ with an $\mathrm{OR}$ in the high exposure group of 8.49 (95\% CI 2.93 to 24.67) among applicators. Similar analyses using the median value of daily exposure showed comparable effects although somewhat stronger than as for cumulative exposure (table 4).

Sensitivity analyses using the $\mathrm{FEV}_{1} / \mathrm{FVC}$ ratio as a continuous outcome resulted in similar results. Correction of the respiratory analyses for height and weight as separate indicators instead of BMI did not change the results materially (see online supplementary tables S3 and S4).

\section{DISCUSSION}

This study investigated the association of occupational pesticide exposure with respiratory symptoms and lung function parameters through detailed occupational pesticide exposure assessment in the recently intensifying agricultural sector of Ethiopia. The result indicated significant exposure-response associations of occupational pesticide exposure with respiratory symptoms and reduced lung function. As these results were observed in

Table 2 Prevalence of respiratory symptoms and lung function parameters by survey, exposure status and job tasks

\begin{tabular}{|c|c|c|c|c|c|c|c|c|c|c|}
\hline \multirow[b]{3}{*}{ Respiratory symptoms } & \multicolumn{5}{|c|}{ First survey (2012) } & \multicolumn{5}{|c|}{ Second survey (2014) } \\
\hline & \multicolumn{2}{|c|}{ Exposed $(n=588)$} & \multicolumn{2}{|c|}{$\begin{array}{l}\text { Unexposed } \\
(n=497)\end{array}$} & \multirow[b]{2}{*}{$p$ Value } & \multicolumn{2}{|c|}{ Exposed $(n=205)$} & \multicolumn{2}{|c|}{ Unexposed $(n=177)$} & \multirow[b]{2}{*}{$p$ Value } \\
\hline & $\mathbf{n}$ & Per cent & $\mathbf{n}$ & Per cent & & $\mathbf{n}$ & Per cent & $\mathbf{n}$ & Per cent & \\
\hline Chronic cough & 36 & 6.0 & 12 & 2.40 & $<0.05^{* *}$ & 26 & 12.60 & 7 & 3.90 & $<0.05^{* *}$ \\
\hline Chronic phlegm & 9 & 1.5 & 4 & 1.00 & 0.28 & 12 & 5.80 & 4 & 2.20 & 0.07 \\
\hline Wheezing & 13 & 2.2 & 5 & 1.00 & 0.13 & 26 & 12.60 & 15 & 8.30 & 0.17 \\
\hline \multirow[t]{2}{*}{ Shortness of breath } & 35 & 5.8 & 7 & 1.40 & $<0.05^{* * *}$ & 58 & 28.20 & 22 & 12.20 & $<0.05^{* *}$ \\
\hline & & & & & & \multicolumn{2}{|c|}{ Exposed applicators $(n=103) \dagger$} & \multicolumn{2}{|c|}{ Unexposed $(n=102) \dagger$} & \\
\hline Lung function (male) & Mean & SD & Mean & SD & - & Mean & SD & Mean & SD & $\mathrm{p}$ Value \\
\hline FVC (L) & - & - & - & - & - & 4.25 & 0.63 & 4.31 & 0.59 & 0.47 \\
\hline $\mathrm{FEV}_{1}(\mathrm{~L})$ & - & - & - & - & - & 3.51 & 0.56 & 3.67 & 0.50 & $<0.05^{*}$ \\
\hline \multirow[t]{2}{*}{ FEF $25 \%-75 \%(\mathrm{~L} / \mathrm{s})$} & - & - & - & - & - & 3.94 & 1.26 & 4.52 & 1.17 & $<0.05^{* * *}$ \\
\hline & & & & & & $\mathrm{n}$ & Per cent & $\mathrm{n}$ & Per cent & \\
\hline $\mathrm{FEV}_{1} / \mathrm{FVC}<0.8$ & - & - & - & - & - & 38 & 30.16 & 9 & 8.04 & $<0.05^{* * *}$ \\
\hline \multicolumn{6}{|l|}{ Lung function (female) } & \multicolumn{2}{|c|}{ Exposed re-entry workers $(n=56)$} & \multicolumn{2}{|c|}{ Unexposed $(n=55)$} & $p$ Value \\
\hline FVC (L) & - & - & - & - & - & 3.15 & 0.49 & 3.27 & 0.43 & 0.22 \\
\hline $\mathrm{FEV}_{1}(\mathrm{~L})$ & - & - & - & - & - & 2.63 & 0.45 & 2.79 & 0.37 & $<0.05^{*}$ \\
\hline \multirow[t]{2}{*}{ FEF $25 \%-75 \%(\mathrm{~L} / \mathrm{s})$} & - & - & - & - & - & 3.06 & 0.89 & 3.56 & 0.89 & $<0.05^{* *}$ \\
\hline & - & - & - & - & - & $\mathrm{n}$ & Per cent & $\mathrm{n}$ & Per cent & \\
\hline $\mathrm{FEV}_{1} / \mathrm{FVC}<0.8$ & - & - & - & - & - & 16 & 25.81 & 8 & 13.33 & 0.10 \\
\hline
\end{tabular}


Table 3 Adjusted ORt for respiratory symptoms among all exposed workers, male applicators, and male and female re-entry farm workers by estimated cumulative pesticide exposure

\begin{tabular}{|c|c|c|c|c|}
\hline Respiratory symptoms & $\begin{array}{l}\text { Chronic cough } \\
\text { OR }(95 \% \mathrm{Cl})\end{array}$ & $\begin{array}{l}\text { Chronic Phlegm } \\
\text { OR }(95 \% \mathrm{Cl})\end{array}$ & $\begin{array}{l}\text { Wheeze } \\
\text { OR ( } 95 \% \mathrm{Cl})\end{array}$ & $\begin{array}{l}\text { Shortness of breath } \\
\text { OR }(95 \% \mathrm{CI})\end{array}$ \\
\hline \multicolumn{5}{|l|}{ First survey } \\
\hline \multicolumn{5}{|l|}{ Pesticide exposure } \\
\hline Unexposed $(n=497)$ & 1.00 & 1.00 & 1.00 & 1.00 \\
\hline Exposed $(n=588)$ & $3.15^{* *}(1.56$ to 6.36$)$ & 2.02 (0.58 to 7.01$)$ & 3.16 (0.96 to 10.47$)$ & $6.67^{* * *}(2.60$ to 17.58$)$ \\
\hline \multicolumn{5}{|l|}{ Male applicators } \\
\hline Unexposed $(n=250)$ & 1.00 & - & - & 1.00 \\
\hline$<$ Median $(n=126)$ & $6.16^{*}(1.24$ to 32.89$)$ & - & - & $22.38^{* *}$ (3.86 to 129.47$)$ \\
\hline$\geq \operatorname{Median}(n=124)$ & $8.14^{*}(1.59$ to 41.42$)$ & - & - & $12.95^{* *}(2.54$ to 65.86$)$ \\
\hline \multicolumn{5}{|l|}{ Female re-entry workers } \\
\hline Unexposed $(n=247)$ & 1.00 & 1.00 & 1.00 & 1.00 \\
\hline$<$ Median $(n=132)$ & 1.54 (0.46 to 5.18$)$ & $1.42(0.22$ to 9.25$)$ & 1.16 (0.17 to 7.58$)$ & 2.12 (0.41 to 10.85$)$ \\
\hline$\geq$ Median $(n=138)$ & $3.02^{*}(1.06$ to 8.58$)$ & $0.57(0.06$ to 6.00$)$ & $1.96(0.39$ to 9.77$)$ & $7.86^{* *}(2.10$ to 29.45$)$ \\
\hline \multicolumn{5}{|l|}{ Male re-entry workers } \\
\hline Unexposed $(n=250)$ & 1.00 & - & - & - \\
\hline$<$ Median $(n=35)$ & $10.16^{*}(1.20$ to 85.89$)$ & - & - & - \\
\hline$\geq$ Median $(n=33)$ & $21.24 * *$ (3.78 to 119.16$)$ & - & - & - \\
\hline \multicolumn{5}{|l|}{ Second survey } \\
\hline \multicolumn{5}{|l|}{ Pesticide exposure } \\
\hline Unexposed $(n=177)$ & 1.00 & 1.00 & 1.00 & 1.00 \\
\hline Exposed $(n=205)$ & $5.76^{* *}(1.90$ to 17.42$)$ & 2.98 (0.76 to 11.58$)$ & $1.75(0.81$ to 3.78$)$ & $4.09 * * *(2.12$ to 7.90$)$ \\
\hline \multicolumn{5}{|l|}{ Male applicators } \\
\hline Unexposed $(n=112)$ & 1.00 & 1.00 & 1.00 & 1.00 \\
\hline$<$ Median $(n=71)$ & $6.69 *(1.03$ to 43.48$)$ & $4.80(0.61$ to 38.13$)$ & 1.97 (0.48 to 8.01$)$ & 2.61 (0.88 to 7.69$)$ \\
\hline$\geq$ Median $(n=71)$ & $13.15^{* *}(2.90$ to 59.53$)$ & 4.67 (0.88 to 24.73$)$ & $4.65^{*}(1.55$ to 13.91$)$ & $6.62 * * *(2.09$ to 16.94$)$ \\
\hline \multicolumn{5}{|l|}{ Female re-entry workers } \\
\hline Unexposed $(n=65)$ & 1.00 & 1.00 & 1.00 & 1.00 \\
\hline$<$ Median $(\mathrm{n}=31)$ & $6.90(0.70$ to 67.70$)$ & $0.98(0.04$ to 026.29$)$ & 1.05 (0.19 to 5.72$)$ & $6.23^{*}(1.50$ to 25.73$)$ \\
\hline$\geq$ Median $(n=31)$ & $3.00(0.31$ to 29.00$)$ & to & 0.68 (0.11 to 4.22$)$ & $6.51^{* *}(1.70$ to 24.82$)$ \\
\hline
\end{tabular}

$(-)$ No estimated OR because of uncertainty in maximum likelihood as a result of small number of observations.

${ }^{*} \mathrm{p}<0.05,{ }^{* *} \mathrm{p}<0.01,{ }^{* * *} \mathrm{p}<0.001$; in bold.

tThe ORs were adjusted for gender (where relevant), age, smoking status, history of pneumonia, income, and marital and khat chewing status.

two consecutive surveys it strengthens the notion that pesticide exposure in these circumstances are related to impaired lung health. Remarkably, these effects on lung health occurred in young subjects (on average 27 years) working only for a relatively short period (on average 4 years).

Our study is the largest to date in sub-Saharan Africa and focused on both, self-reported respiratory symptoms and objective lung function measurements. Besides the large study size, we performed a detailed semiquantitative exposure assessment allowing exposure-response analyses. However, the study also had several limitations. First lack of specific pesticide data is a main limitation of our study. The others are: due to the anonymous participation in the first survey we were not able to determine if there was overlap in the workforce between the two surveys. However, as we selected a random subpopulation of workers of these farming systems, and as workers tend to work in general only for a short time at these farms, ${ }^{20} 25$ we expect the overlap between the two surveys, which were conducted 2 years apart, to be low. As the two surveys were crosssectional there is the potential for a 'health worker selection' bias. We do not know the extent of this problem but if present would have led to an underestimation of the effects described in this study. Another limitation is that we observed a significant increase in prevalence of respiratory symptoms in the second survey than the first. This difference was present among both the exposed and unexposed groups suggesting different ascertainment and reporting between the two surveys. As the two surveys included the same source population, and was conducted in the same season, and as the period between the two surveys was only 2 years apart it is unlikely that the background prevalence of these symptoms in the population had significantly changed. As we kept the questionnaire similar between the two surveys the most plausible reason is that a difference in the trained interviewers and familiarity with the instruments resulted in these differences.

Hanssen $e$ t $a l^{18}$ reported prevalences of $43.7 \%$ and $70.2 \%$ for chronic cough and shortness of breath among farm workers in Ethiopia. These prevalences were more similar to the prevalences observed in the second survey, possibly suggesting that disease reporting was more complete in the second survey. If indeed prevalences in the first survey were underascertained, this would mainly limit the direct comparison of the prevalences between the two surveys, but it would not necessarily bias the risk estimates within the survey as long as the underascertainment was independent of exposure status. The latter seems to be the case in our study as the difference in prevalence observed between the two surveys was equal between the unexposed and exposed groups.

We reported a higher prevalence of respiratory symptoms in exposed than unexposed individuals. This effect was seen in both surveys and exhibited a significant exposure-response relation for chronic cough and shortness of breath. This is similar 
Table 4 Cumulative and daily intensity of pesticide exposure and lung function among all exposed workers, male applicators and female re-entry workers (effects are presented as a change in continuous lung function parameters $(\beta) \dagger$ and as OR $\dagger$ for dichotomous variables)

\begin{tabular}{|c|c|c|c|c|}
\hline Respiratory parameters & $\begin{array}{l}\text { FVC (L) } \\
\beta(95 \% \mathrm{Cl})\end{array}$ & $\begin{array}{l}\mathrm{FEV}_{1}(\mathrm{~L}) \\
\beta(95 \% \mathrm{Cl})\end{array}$ & $\begin{array}{l}\mathrm{FEV}_{1} / \mathrm{FVC}<0.8 \\
\text { OR }(95 \% \mathrm{Cl})\end{array}$ & $\begin{array}{l}\text { FEF } 25 \%-75 \%(\mathrm{~L} / \mathrm{s}) \\
\text { 乃 }(95 \% \mathrm{Cl})\end{array}$ \\
\hline \multicolumn{5}{|l|}{ Cumulative exposure } \\
\hline \multicolumn{5}{|l|}{ Exposure status } \\
\hline Unexposed $(n=157)$ & 1.00 & 1.00 & 1.00 & 1.00 \\
\hline Exposed $(n=159)$ & $-0.05(-0.18$ to 0.07$)$ & $-0.14^{* *}(-0.25$ to -0.03$)$ & $4.31^{* * *}(2.11$ to 8.81$)$ & $-0.55^{* * *}(-0.80$ to -0.31$)$ \\
\hline \multicolumn{5}{|l|}{ Male applicators } \\
\hline Unexposed $(n=102)$ & 1.00 & 1.00 & 1.00 & 1.00 \\
\hline$<$ Median $(n=46)$ & $-0.04(-0.28$ to 0.20$)$ & $-0.19(-0.39$ to 0.02$)$ & $8.36 * *(2.36$ to 29.60$)$ & $-0.71^{* *}(-1.17$ to -0.24$)$ \\
\hline$\geq$ Median $(n=57)$ & $-0.06(-0.26$ to 0.15$)$ & $-0.15(-0.33$ to 0.03$)$ & $8.49^{* * *}(2.93$ to 24.67$)$ & $-0.58^{* *}(-0.98$ to -0.19$)$ \\
\hline \multicolumn{5}{|l|}{ Female re-entry workers } \\
\hline Unexposed $(n=55)$ & 1.00 & 1.00 & 1.00 & \\
\hline$<$ Median $(n=29)$ & $-0.01(-0.24$ to 0.23$)$ & $-0.08(-0.29$ to 0.13$)$ & 2.63 (0.65 to 10.68$)$ & $-0.56^{*}(-1.00$ to -0.13$)$ \\
\hline$\geq$ Median $(n=27)$ & $-0.12(-0.36$ to 0.11$)$ & $-0.15(-0.35$ to 0.06$)$ & 1.55 (0.41 to 5.88$)$ & $-0.39(-0.81$ to 0.04$)$ \\
\hline \multicolumn{5}{|l|}{ Daily exposure } \\
\hline \multicolumn{5}{|l|}{ Male applicators } \\
\hline Unexposed $(n=102)$ & 1.00 & 1.00 & 1.00 & 1.00 \\
\hline$<$ Median $(n=46)$ & $0.01(-0.21$ to 0.22$)$ & $-0.11(-0.30$ to 0.07$)$ & $7.64 * * *(2.50$ to 23.34$)$ & $-0.59 * *(-1.00$ to -0.17$)$ \\
\hline$\geq$ Median $(n=57)$ & $-0.10(-0.32$ to 0.10$)$ & $-0.21^{* *}(-0.39$ to -0.03$)$ & $9.34^{* * *}(3.06$ to 28.56$)$ & $-0.69 * *(-1.09$ to -0.27$)$ \\
\hline \multicolumn{5}{|l|}{ Female re-entry workers } \\
\hline Unexposed $(n=55)$ & 1.00 & 1.00 & 1.00 & \\
\hline$<$ Median $(\mathrm{n}=29)$ & $-0.02(-0.21$ to 0.22$)$ & $-0.07(-0.27$ to 0.13$)$ & $1.49(0.38$ to 5.77$)$ & $-0.45^{*}(-0.87$ to -0.02$)$ \\
\hline$\geq$ Median $(n=27)$ & $-0.10(-0.32$ to 0.11$)$ & $-0.16(-0.37$ to 0.05$)$ & $2.52(0.68$ to 9.36$)$ & $-0.50 *(-0.94$ to -0.06$)$ \\
\hline
\end{tabular}

to studies reporting on respiratory symptoms in other LMICs. $^{9}{ }^{10}$ 26-29 A study in LSGHs in Ethiopia reported a similar high risk for respiratory symptoms among cutters and weeders when compared with other unexposed farm workers (packing and bundling) (ie, OR of 2.2 (95\% CI 1.0 to 5.1) and 1.8 (95\% CI 0.9 to 3.8$)$ ) for chronic cough and shortness of breath, respectively. ${ }^{1}$ These risks are lower than the risks observed in our study which possibly can be explained by the fact that the reference workers in packing and bundling might still have the potential for pesticide exposure as indicated by our previously developed exposure algorithm for re-entry workers ${ }^{23}$ and the fact that among these workers' elevated risks for respiratory symptoms were observed in our study.

The reduction of FEF $25 \%-75 \%$ with exposure in our study is in accordance with previous studies in $\operatorname{Spain}^{11}$ and in the Netherlands. $^{30}$ FEF $25 \%-75 \%$, is a sensitive indicator of obstruction in small airways of the lungs ${ }^{31}$ underlining distal airflow limitation with pesticide exposure. Similar to previous studies in LSOFs in Ethiopia ${ }^{19} 20$ we showed a significant reduction in $\mathrm{FEV}_{1}$ in pesticide exposed as compared with unexposed controls.

A study in Korean farm workers indicated an exposureresponse relationship between the risk of restrictive ventilator defects and duration of paraquat application. ${ }^{32}$ This is comparable to our result of an exposure-response trend between cumulative exposure and risk of $\mathrm{FEV}_{1} / \mathrm{FVC}<0.8$ though the effect seen in the high exposure group of our study is larger than that observed in the Korean study (ie, ORs of 8.48 and 1.89, respectively). Also a study in the Netherlands indicated an association of occupational pesticide exposure with reduction in $\mathrm{FEV}_{1}$ in an exposure-dependent way. ${ }^{33}$ Again the effects observed in our study showed stronger effects than those reported in the Dutch study with a reduction in $\mathrm{FEV}_{1}$ of $210 \mathrm{~mL}$ in the high exposure group compared with $94 \mathrm{~mL}$ in the study in the Netherlands.

Though there is a difference in methodology if we compare the reduction in $\mathrm{FEV}_{1}$ due to pesticide exposure (ie, $140 \mathrm{~mL}$ ) in our study with a standardised estimate of pulmonary function loss due to cigarette smoking (ie, $12.6 \mathrm{~mL} /$ year and $7.2 \mathrm{~mL} /$ year of smoking one pack of cigarettes daily for a year, respectively, in men and women), ${ }^{34}$ then the observed effect is comparable to the effect due to smoking of one pack of cigarettes per day continuously for 11 years and 19 years in men and women, respectively.

In conclusion two consecutive surveys and an independent recent survey have indicated exposure-dependent effects of occupational pesticide exposure on respiratory symptoms and lung function decline in farmers and farm workers in contemporary Ethiopian agriculture. Our results are alarming in that the reported respiratory health risks are significant in magnitude and that they were seen within a short duration of pesticide exposure (4 years on average). The most evident reasons for the respiratory risk observed among exposed workers include poor pesticide-related knowledge and practices likely resulting in relatively high exposure events. Absence of occupational safety and health personnel with appropriate training in most of the surveyed farms will have contributed to this undesirable situation. The results of our study warrant implementation of strict risk management measures in the recently intensifying agriculture sector of Ethiopia.

Contributors Conception and design: BN, HK, RV and YM. Collection of the data: $\mathrm{BN}$ and YM. Analysis and interpretation: BN, HK and RV. All authors participated in drafting and finally approving the manuscript. 
Funding This study was supported by the Pesticide Risk Reduction Programme (PRRP) Ethiopia. PRRP was a comprehensive programme for pesticide registration and management started in 2010 and lasted till 2015. The following donors funded the programme: Ministry of Agriculture and Rural Development of Ethiopia by making available sufficient qualified personnel to execute the activities, the government of the Netherlands, represented by the Ministry of Development Cooperation, Food and Agriculture Organization of the United Nations and the Strategic Approach to International Chemicals Management, a policy framework to promote chemical safety around the world. The sponsors have no involvement in the study design; in the collection, analysis and interpretation of the data; in the writing of the report; and in the decision to submit the paper for publication.

\section{Competing interests None.}

Ethics approval The study was approved by the Institutional Review Board of the College of Natural Sciences Addis Ababa University, Ethiopia.

Provenance and peer review Not commissioned; externally peer reviewed.

\section{REFERENCES}

1 Strong LL, Thompson B, Coronado GD, et al. Health symptoms and exposure to organophosphate pesticides in farmworkers. Am J Indu Med 2004:46:599-606.

2 Damalas CA, Eleftherohorinos TG. Pesticide exposure, safety issues, and risk assessment indicators. Int J Environ Res Pub Health 2001;8:1402-19.

3 Fareed M, Pathak Manoj K, Bihari V, et al. Hematological and biochemical alterations in sprayers occupationally exposed to mixture of pesticides at a mango plantation in Lucknow, India. Toxicol Environ Chemi 2010:92:1919-28.

4 Penagos HG. Contact dermatitis caused by pesticides among banana plantation workers in Panama. Int J Occup Environ Health 2002;8:14-18.

5 Colosio C, Birindelli S, Corsini E, et al. Low level exposure to chemicals and immune system. Toxi Appl Pharma 2005;207:320-8.

6 Naidoo S, London L, Burdorf A, et al. Spontaneous miscarriages and infant deaths among female farmers in rural South Africa. Scand I Work Environ Health 2011;37:227-36.

7 London L, Beseler C, Bouchard MF, et al. Neurobehavioral and neurodevelopmental effects of pesticide exposure. Neurotoxicology 2012;33:887-96.

8 Fareed M, Pathak MK, Bihari V, et al. Adverse respiratory health and hematological alterations among agricultural workers occupationally exposed to organophosphate pesticides: a cross-sectional study in North India. PLOS ONE 2013;8:e69755.

9 Chakraborty S, Mukherjee S, Roychoudhury S, et al. Chronic exposures to cholinesterase-inhibiting pesticides adversely affect respiratory health of agricultural workers in India. J Occup Health 2009;51:488-97.

10 Faria NMX, Facchini LA, Fassa AG, et al. Pesticides and respiratory symptoms among farmers. Rev Saude Pub/ 2005;39:973-81.

11 Hernández AF, Casado I, Pena G, et al. Low level of exposure to pesticides leads to lung dysfunction in occupationally exposed subjects. Inhal Toxicol 2008;20:839-49.

12 Hoppin JA, Umbach DM, London SJ, et al. Pesticides and adult respiratory outcomes in the agricultural health study. Ann N Y Acad Sci 2006;1076:343-54.

13 Salameh PR, Waked M, Baldi I, et al. Chronic bronchitis and pesticide exposure: a case-control study in Lebanon. Eur J Epidemiol 2006;21:681-8.

14 Schenker MB, Stoecklin M, Lee K, et al. Pulmonary function and exercise-associated changes with chronic low-level paraquat exposure. Am J RespirCrit Care Med 2004; 170:773-9.
15 Zuskin E, Mustajbegovic J, Schachter EN, et al. Respiratory function in pesticide workers. J Occup Environ Med 2008;50:1299-305.

16 Labour proclamation number 377/2003. Serial online, 2004 Feb (cited 10 February 2016). http://www.molsa.gov.et/mobile/Resources/EthLabourPro377.pdf

17 Ejigu D, Mekonnen Y. Pesticide use on agricultural fields and health problems in various activities. East Afr Med J 2005;82:427-32.

18 Hanssen VM, Nigatu AW, Zeleke ZK, et al. High prevalence of respiratory and dermal symptoms among Ethiopian flower farm workers. Arch Environ Occup Health 2015:70:204-13.

19 Mekonnen Y, Agonafir T. Effects of pesticide applications on respiratory health of Ethiopian farm workers. Int J Occup Environ Health 2002;8:35-40.

20 Mekonnen $Y$, Agonafir T. Lung function and respiratory symptoms of pesticide sprayers in state farms of Ethiopia. EthiopMed J 2004;42:261-6.

21 Negatu B, Kromhout H, Mekonnen Y, et al. Use of Chemical Pesticides in Ethiopia: a cross-sectional comparative study on Knowledge, Attitude and Practice of farmers and farm workers in three farming systems. Ann Occup Hyg 2016;60:551-66.

22 Miller MR, Hankinson J, Brusasco V, et al., ATS/ERS Task Force. Standardization of spirometry. Eur Respir J 2005;26:319-38.

23 Negatu B, Vermeulen $R$, Mekonnen $Y$, et al. A method for semi-quantitative assessment of exposure to pesticides of applicators and re-entry workers: An application in three farming systems in Ethiopia. Ann Occup Hyg 2016:60:669-83.

24 Dosemeci M, Alavanja MCR, Rowland AS, et al. A quantitative approach for estimating exposure to pesticides in the Agricultural Health Study. Ann of Occup Hyg 2002;46:245-60.

25 Nigatu AW, Bråtveit M, Deressa W, et al. Respiratory symptoms, fractional exhaled nitric oxide and endotoxin exposure among female flower farm workers in Ethiopia. J Occup Med Toxicol 2015;10:8.

26 Beshwari MMM, Bener A, Ameen A, et al. Pesticide-related health problems and diseases among farmers in the United Arab Emirates. Int I Environ Health Research 1999:9:213-21.

27 Abu Sham'a F, Skogstad M, Nijem K, et al. Lung function and respiratory symptoms in male Palestinian farmers. Arch Environ Occup Health 2010;65:191-200.

28 Callahan CL, Al-Batanony M, Ismail AA, et al. Chlorpyrifos exposure and respiratory health among adolescent agricultural workers. Int J Environ Res Public Health 2014;11:13117-29.

29 Fieten $\mathrm{KB}$, Kromhout $\mathrm{H}$, Heederik $\mathrm{D}$, et al. Pesticide exposure and respiratory health of indigenous women in Costa Rica. Am J Epidemol 2009;169:1500-6.

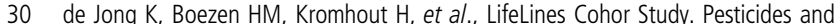
other occupational exposures are associated with airway obstruction: the LifeLines cohort study. Occup Environ Med 2014;71:88-96.

31 Seaton A, Crompton G. Asthma: clinical features. In: Seaton A, Seaton D, Leitch $A G$, eds. Crofton and Douglas's respiratory diseases. 5th edn. Oxford: Blackwell, 2000:77-151.

32 Cha ES, Lee YK, Moon EK, et al. Paraquat application and respiratory health effects among South Korean farmers. Occup Environ Med 2012;69:398-403.

33 de Jong K, Boezen HM, Kromhout H, et al., LifeLines Cohort Study. Occupational exposure to vapors, gases, dusts, and fumes is associated with small airways obstruction. Am J Respir Crit Care Med 2014;189:487-90.

$34 \mathrm{Xu} \mathrm{X}$, Dockery DW, Ware JH, et al. Effects of cigarette smoking on rate of loss of pulmonary function in adults: a longitudinal assessment. Am Rev Respir Dis 1992:146:1345-8. 